\title{
Graphical User Interface Features In Building Attractive And Successful Websites
}

\author{
Ahmed Mahdee Abdo \\ Sardar Hasan Alali \\ Computer Science Department, Zakho University, Kurdistan, Iraq \\ doi: 10.19044/esj.2016.v12n15p332 URL:http://dx.doi.org/10.19044/esj.2016.v12n15p332
}

\begin{abstract}
The process involve in building a successful website goes beyond knowing web developing languages such as HTML and CSS. The success or failure of any website depends heavily on the use of some aspects of Graphical User Interface. These aspects are usually reserved for client's wishes and desires. The content features of the GUI are used to stay in touch with visitors. Therefore, this article will highlight some important GUI features used in building an attractive and a successful website.
\end{abstract}

Keywords: Graphical user interface, attractive, consistency, navigation, websites

\section{Background}

In time past, computer systems uses basic-text to run user's desires. However, it was difficult to even run simple commands. With the invention of the Graphical User Interface (GUI), computers have become easier to use. "GUI is a means of enabling user interaction with electronic devices such as computers or hand-held devices" (Closa et al., 2010). Jansen (1998) shows that the Xerox Star was the first GUI application that was designed by researchers at Xerox Palo Alto research centre in 1977. He further stated that: later, the Apple Company rented some Xerox Star features to design its first GUI system which was called Apple Lisa. However, this was developed shortly after the advent of Apple Macintosh as a commercial computer in 1984. Graphical user interface should involve various significant aspects. Thus, these aspects help to make the interface easy, attractive, and effective. Some of these aspects include consistency, loading time, navigations etc.

\section{The Clients}

Consequently, the most important step before building any user interface is to know the website clients. The users and their wishes are the 
main reason behind building any website. When a user visits a website that meets his/her needs and desires, the user will be motivated to visit the website again and again. Tidwell (2011) shows that designing a good user interface involves more than programming. He adds: A success GUI depends on understanding why the users like, dislike or prefer a specific website or a piece of program and interact with them. User interface designers should be focused on user' characteristics in helping them achieve their goals (Tidwell, 2011; Galitz, 2007). Galitz (2007) shows that GUI is a part of HumanComputer Interaction whereby both the machine and the users interacted as the users find their wishes satisfactorily.

\section{Loading Time}

Users' first impression of a website could also be determined by how much time the website in question would take to load. Palmer (2002) stated that users like websites that loads faster in just few seconds. Subsequently, users are forced to visit other sites when they observe that a website is taking so much time to load (Plumley, 2011; Palmer, 2002). However, the loading time of a website could be decreased by following some techniques such as using fewer images, using separate video host server such as YouTube, and putting CSS and java scripts files separately from HTML files. Users prefer websites that serves them well, and that helps them in achieving their desires faster. Moreover, there are some tools that might help the designer to know in details how much the site takes to load. An example of such tools is browser's plug-ins and online services. However, websites are the worst places to test the user's patience.

\section{Consistency}

Consistency in the designing of websites is a very significant aspect in the world of web design. This entails widening the user satisfaction and user knowledge about the website (Koyani et al., 2004, cited in Galitz, 2007). Ozok \& Salvendy (2004) cited in Galitz (2007), claims that users deal easily with the website that is designed consistently from linguistics and visual points of view. Consistency means how the website looks like? Is there harmony between the site colours, font size, menu list, and every single detail of the website? In addition, the images, videos, background colour, and other tools that are used to get the user's attentions should support the site purposes; however, these should not distract them, but should be used in their suitable places (Plumley, 2011). Moreover, GUI consistency means that the GUI should be displayed in a good manner in all kind of browsers such as Internet explorer and Google chrome. Furthermore, consistency means how the elements of the GUI are arranged to support the website goals and the user's attention. 


\section{Search and Lists}

Another characteristic of a good website is to provide its users with good tools that facilitate effective information browsing. A good designer presents an appropriate user interface which accomplishes the user's wishes in just a few clicks (Lynch et al., 2008; Tidwell, 2011). In addition, if the visitors find their desires easily and feel confident with the website, this will stimulate them to continue even if they face some difficulties later (Tidwell, 2011). Also, this could be done by using some specific tools such as menu list and search box. Research on user interface shows that half of the web visitors like the menu list for exploring information, while others go directly to the search box in the web to search through the web (Lynch et al., 2008). However, the search boxes could be seen in most websites because it is used to look for information faster. In addition, users tend to prefer the website which serves them as quickly as possible.

\section{Navigations}

Navigation can also be added to the list of the features of a good user interface. Plumley (2011) claims that an effective website has effective tools for connecting enormous amount of information together. The main goal of the navigations is to guide the visitors to browse the information from a more general to more specific information. Thus, an example is shopping website. They are used for helping people to know on which page they are, and how to return to the home page or other important pages without wasting time (Lynch et al., 2008). Furthermore, important links such as home page, contact, social media links, FAQ, and help might be shown on every page of the web. Hence, navigations is considered as a guide of a web which involves all significant details about the web

\section{Easy Form}

It is of immense importance that visitors do not find any difficulty when they register with the website. Jarrett \& Gaffney (2008) revealed that people are filling forms widely. Thus, this is seen wherever they are logging to an email, signing to credit card details, buying and selling online, and applying for study. They added: "Since the forms are frequently used, the design of the form does matter. Poor quality form could lead to serious consequences such as leaving or it makes the website less common. However, good quality form might be implemented by using some techniques that make the form friendlier." Tidwell (2011) claims that this could be achieved by visibly marking important fields and deferring unnecessary ones to be filled after completing the registration. A good registration form, according to Tidwell, is one that could save information even if the users did not complete all fields that allow them return later to 
complete the registration. In other words, a good registration form helps users to get registered simply and swiftly.

\section{Contact}

One of the other important features of a good GUI is how the users get in touch with the person in charge of the website. The most common way by which users keep in touch with the responses of the website is by adding a contact button (Plumley, 2011). This will help the users to give feedback, know more, and ask every single detail about the website or about the services that the website provides. Usually, there are two locations of the contact button in the website, either at the down of the page in the footer location or up and near the main navigation as a small button (Plumley, 2011). In addition, the contact button contains information such as address, phone number, mail box number, and operation hours. Moreover, social media website could also be used to get in touch with the users such as Facebook and Twitter. Therefore, these tools are helpful in having a dialog between the visitors and the website.

\section{Help \& FAQ}

A final feature of a high-quality user interface is related to its ability to solve problems that visitors may face when using the web. This could be done by adding help and FAQ pages to the website. Plumley (2011) states that the FAQ page refers to the most frequently asked questions by the web users. However, these questions are the most common concerns of the users about the page or about how to use the web page. FAQ should have an obvious link that appears on all pages. This is used to guide the user and find the needed information easily. The help page is meant to help users follow certain steps required to solve a problem (Galitz, 2007). Thus, these instruments help to guide new visitors who do not have enough knowledge about the web.

\section{Conclusion}

User interface could be the key to the success or the failure of a website. It involves many important principles which make the interface usable and accessible. The success of user interface relies heavily on many aspects. Some of these principles are related to the website appearance such as consistency. Others are related to content such as navigation. In addition, good user interface is one that serves its users easily. All of these aspects are beyond knowing website programming language. Therefore, they should be known and taken into account before building any website. 


\section{References:}

Bernard (1988). The graphical user interface ACM SIGCHI Bulletin.

Closa et al. (2010). Patent law for computer scientists: steps to protect computer-implemented inventions. Berlin: Springer.

Galitz (2007). The essential guide to user interface design: an introduction to GUI design principles and techniques. Indiana: Wiley.

Jarrett \& Gaffney (2008). Forms that work. Brookline, Massachusetts.

Lynch \& Horton (2008). Web style guide: basic design principles for creating Web sites. London: Yale University Press.

Palmer (2002). Designing for website usability. The Institute of Electrical and Electronics Engineers, Inc, 35(7).

Plumley (2011). Website design and development: 100 questions to ask before building a website. Indiana: Wiley.

Tidwell (2011). Designing Interface. Sebastopol: O’Reilly. Jarrett \& Gaffney (2008). Forms that work. Brookline, Massachusetts. 